\title{
Comparison of different intraocular pressure measurement techniques in normal eyes, post surface and post lamellar refractive surgery
}

This article was published in the following Dove Press journal:

Clinical Ophthalmology

7 January 2013

Number of times this article has been viewed

\section{Shireen MA Shousha Mahmoud AH Abo Steit Mohamed HM Hosny Wael A Ewais \\ Ahmad MM Shalaby}

Department of Ophthalmology, Faculty of Medicine, Cairo University, Cairo, Egypt
Correspondence: Ahmad MM Shalaby Department of Ophthalmology, Faculty of Medicine, Cairo University,

70 El-Manyal Street, El-Basha Square,

Cairo, Egypt I|45।

Tel +20223631008

Fax +20233307073

Email ammshalaby@kasralainy.edu.eg
Background: The purpose of this study was to determine the accuracy of intraocular pressure (IOP) measurement after laser in situ keratomileusis (LASIK) or epithelial laser in situ keratomileusis (Epi)-LASIK using Goldmann applanation tonometry, air puff tonometry, ocular response analyzer corneal compensated IOP (ORA IOPcc) and Pentacam corrected IOP.

Methods: A prospective comparative clinical study was conducted between February and September 2011 on 30 eyes divided into four groups, i.e. 20 corneas of 10 patients before LASIK (group A), 20 corneas of the same patients 2 months postoperatively (group B), 10 corneas of five patients before Epi-LASIK (group C), and 10 corneas of the same patients 2 months postoperatively (group D). Patient age ranged from 20 to 50 years. IOP was measured using Goldmann applanation and air puff tonometry, ORA corneal compensation, and Pentacam correction (which also measured central corneal thickness).

Results: Significant positive linear correlations were found between IOP values measured by Goldmann applanation tonometry and other techniques, and with preoperative pachymetry in group A. The correlation between preoperative Pentacam-corrected and preoperative ORA corneal-compensated IOP was strongest for Goldmann applanation tonometry $(r=0.97$ and $\mathrm{r}=0.858$ respectively, $P<0.001$ ). Compared with preoperative values, postoperative IOP measured by the four methods were significantly lower. The difference was statistically significant when IOP was measured using Goldmann applanation and air puff tonometry compared with the ORA and Pentacam methods $(P<0.001$ for LASIK patients and $P=0.017$ for Epi-LASIK patients). Nonsignificant correlations were found between the degree of lowering of postoperative IOP and postoperative pachymetry in groups B and D.

Conclusion: Refractive surgery causes significant lowering of IOP as measured using Goldmann applanation tonometry, air puff tonometry, ORA compensation, and Pentacam correction. LASIK has a greater effect than Epi-LASIK on IOP measurement error following refractive surgery.

Keywords: intraocular pressure measurement, refractive surgery, corneal biomechanics, corneal thickness

\section{Introduction}

Measurement of intraocular pressure (IOP) plays a central role throughout ophthalmology. It is part of routine ophthalmologic examinations and important in the management and follow-up of patients with glaucoma. ${ }^{1}$ While elevated IOP remains the most important risk factor for development ${ }^{2}$ and progression of open angle glaucoma, ${ }^{3}$ at least half of the population diagnosed with open angle glaucoma is asymptomatic. ${ }^{1}$

Refractive surgery, mostly laser-assisted in situ keratomileusis (LASIK), has become increasingly popular in recent years. However, structural modification 
of corneal properties, eg, central corneal thickness and corneal curvature by refractive surgery has increased the risk of IOP measurement error and consequently focused attention on the methods used to measure IOP. New methods for IOP measurement and assessing corneal biomechanics are continuously under study and evaluation.

In this study, we evaluated the ease and accuracy of IOP measurement before and after refractive surgery (LASIK and epithelial [Epi]-LASIK) using applanation tonometry, air puff tonometry, an ocular response analyzer (ORA), and a Scheimpflug camera (Pentacam ${ }^{\circledR}$, OCULUS Optikgerate GmbH, Wetzlar, Germany), comparing post-LASIK and post-Epi-LASIK groups to determine the effect of lamellar refractive surgery versus surface ablation on IOP measurements obtained after each type of procedure.

\section{Materials and methods \\ Study design}

This was a prospective comparative clinical study between February 2011 and September 2011 of 30 eyes divided into four groups. Groups A and B included 20 corneas of 10 patients before and after undergoing LASIK surgery, respectively. Groups C and D included 10 corneas of five patients before and after Epi-LASIK surgery, respectively. We included patients who were candidates for refractive surgery (LASIK and Epi-LASIK) and aged 20-50 years, with clear corneas, moderate myopia of -2 to -6 diopters, and stable refraction. Patients with ocular pathology, such as corneal scarring or keratoconus, and those with any previous anterior segment surgery were excluded.

\section{Preoperative assessment}

A complete ocular and medical history was obtained, with particular attention paid to the presence of collagen vascular disease, hormonal changes such as pregnancy, previous refractive or other anterior segment surgery, ocular injuries, and vitreoretinal surgery or disease. Medications and allergies were also noted. Written informed consent was obtained after detailed instruction and discussion. Soft contact lens wearers were required to leave their lenses out for one week, and 2 weeks for hard and rigid gas-permeable lenses. All patients underwent the following tests before surgery: autorefractometry, corneal topography, uncorrected visual acuity and best-corrected visual acuity for far distances, slit-lamp examination, dilated fundus examination, and pachymetry using the Pentacam camera with the basic software package. Intraocular pressure was measured using a slit-lamp-mounted Goldmann applanation tonometer (Haag-Streit, Bern, Switzerland), an air puff tonometer (Reichert Ophthalmic Instruments, Depew, NY), an ORA (Reichert Ophthalmic Instruments, model 30 classic, software version 2.0, Depew), or a Scheimpflug (Pentacam) camera. Pentacam-corrected IOP was calculated using the Ehlers formula, being the only one available in our version of the machine, using Goldmann applanation tonometry values.

\section{Surgical technique}

All surgeries were undertaken by the same surgeon $(\mathrm{MH})$. LASIK was performed under topical anesthesia (benoxinate hydrochloride 0.4\%) using Visx S4 IR (Abbott Medical Optics Inc, Santa Ana, CA) and an automated microkeratome (Moria SA, Antony, France, $90 \mu \mathrm{m}$ blade), with a disposable head to produce a superiorly hinged flap. EpiLASIK was done using an epikeratome (a preassembled dull separator and a suction ring producing a nasal hinge flap that is removed). Balanced salt solution chilled to $4^{\circ} \mathrm{C}$ was instilled for anesthesia as part of our routine technique. Mitomycin C $0.02 \%$ was applied for 12 seconds after performing laser ablation, followed by washing in balanced salt solution chilled to $4^{\circ} \mathrm{C}$ and application of a bandage contact lens.

\section{Postoperative assessment}

In addition to routine assessment, pachymetry and IOP were re-evaluated 2 months after performing the refractive surgery using the same devices.

\section{Statistical analysis}

Statistical analysis was performed using the Statistical Package for Social Sciences version 16 (SPSS Inc, Chicago, IL). Firstly, all variables were tested for normality using the Kolmogorov-Smirnov test. The test was significant, and non-normality was accepted for all variables. Accordingly, quantitative data are presented as the median (range), while qualitative data are presented as the number (percentage). Because not all quantitative data were normally distributed, the variables were compared between two related samples using Wilcoxon's test and two unrelated samples using the Mann-Whitney $\mathrm{U}$ test. $P<0.05$ was considered to be statistically significant. Furthermore, bivariate correlations were performed between different parameters using the Spearman correlation coefficient (r). $\Delta$ for a variable was calculated by subtracting the postoperative value from the preoperative value. 


\section{Results}

Our LASIK patients were aged $20-50$ years, with $30 \%$ being men, and our Epi-LASIK patients were aged 20-31 years, with $20 \%$ being men. Patient demographics, preoperative and postoperative pachymetry, and IOP values for LASIK and Epi-LASIK patients are shown in Table 1.

Significant positive linear correlations were found preoperatively between IOP values measured by Goldmann applanation tonometry and those measured by air puff tonometry, Pentacam correction and ORA corneal compensation, as well as central corneal thickness by pachymetry in LASIK patients (group A). The correlation between preoperative Pentacam-corrected and ORA corneal-compensated IOP was the strongest with Goldmann applanation tonometry ( $\mathrm{r}=0.97$ and $\mathrm{r}=0.858$, respectively, $P<0.001$ ). Significant positive linear correlations were also obtained in Epi-LASIK patients (group C). Furthermore, correlations were sought for all LASIK and Epi-LASIK patients together (by adding group A to C) and stronger correlations were found (Table 2, Figure 1).

Using the Wilcoxon test, these results were confirmed for groups $\mathrm{A}$ and $\mathrm{C}$ and all the study patients (group $\mathrm{A}+\mathrm{C}$ ) preoperatively by a statistically significant difference between preoperative Goldmann applanation and air puff tonometry $(P=0.016$ group $\mathrm{A}, P=0.009$ group $\mathrm{C}, P=0.001$ group $\mathrm{A}+\mathrm{C})$ and no statistically significant difference when comparing preoperative IOP measured by Goldmann applanation tonometry and Pentacam correction ( $P=0.6$ for group A, $P=0.112$ for group $\mathrm{C}, P=0.789$ for groups $\mathrm{A}+\mathrm{C}$ ) or by ORA corneal compensation ( $P=0.92$ for group A, $P=0.889$ for group $\mathrm{C}, P=0.982$ for groups $\mathrm{A}+\mathrm{C}$ ).

Comparing the difference between preoperative Pentacam-corrected IOP and Goldmann applanation tonometry values [group A median $0.3(-1.7,-1.6)$, group $\mathrm{C}$ median $-0.5(-0.6,-0.2)$, and group $\mathrm{A}+\mathrm{C}$ median 0.0 $(-1.7,-1.6)]$ with the difference between preoperative ORA corneal compensation and Goldmann applanation tonometry [group A median $-0.35(-3.7,-6.6)$, group C median $0.0(-1.1,-1.2)$, and group $\mathrm{A}+\mathrm{C}$ median -0.15 $(-3.7,-6.6)]$ did not show a statistically significant difference between the patient groups $(P=0.67,0.72$, and 0.73 for groups $\mathrm{A}, \mathrm{C}$, and $\mathrm{A}+\mathrm{C}$, respectively). However, comparing the difference between preoperative Pentacam-corrected and Goldmann applanation tonometry IOP [group A median 0.3 $(-1.7,-1.6)$, group C median $-0.5(-0.6,-0.2)$, and group A + $\mathrm{C}$ median $0.0(-1.7,-1.6)]$ with the difference between air puff and Goldmann applanation tonometry IOP [group A median -2.0 (-4.0, -5.0), group C median -1.5 (-2.0, -0.0) and group A + C median -2.0 (-4.0, -5.0)] showed a statistically significant difference between all patient groups $(P=0.011,0.011$, and 0.001 for groups $\mathrm{A}, \mathrm{C}$, and $\mathrm{A}+\mathrm{C}$, respectively), which confirms the previous results.

Table I Demographics, pre- and postoperative IOP values for LASIK and EpiLASIK patients

\begin{tabular}{|c|c|c|c|}
\hline \multirow[t]{2}{*}{ Variable } & \multirow{2}{*}{$\begin{array}{l}\text { LASIK patients } \\
\text { "Group A and B" } \\
(n=40 \text { eyes) }\end{array}$} & \multirow{2}{*}{$\begin{array}{l}\text { EpiLASIK patients } \\
\text { "Group C and D" } \\
(n=20 \text { eyes) }\end{array}$} & \multirow[t]{2}{*}{$P$} \\
\hline & & & \\
\hline Age, year & $2 \mathrm{I} .5(20-5 \mathrm{I})$ & $22(|9-3|)$ & 1.0 \\
\hline Male, gender & 6 patients ( 12 eyes- $30 \%$ ) & 2 patients ( 4 eyes-20\%) & 0.68 \\
\hline Pach pre, micron & $524(500-600)$ & $482(470-563)$ & 0.003 \\
\hline App pre, $\mathrm{mmHg}$ & I $8(8-28)$ & $14(12-16)$ & 0.009 \\
\hline Pentacam pre, mmHg & $18.15(8.8-27.3)$ & |4.05 (II.8-16.2) & 0.011 \\
\hline Air puff pre, $\mathrm{mmHg}$ & $20(10-28)$ & $15(12-18)$ & 0.005 \\
\hline ORA pre, mmHg & | $8.4(|1|-2 \mid .9)$. & $13.4(12-16)$ & 0.003 \\
\hline Pach post, micron & $46 I(42 I-549)$ & $446(420-502)$ & 0.179 \\
\hline App post, mmHg & $12(6-16)$ & $12(10-14)$ & 0.651 \\
\hline Pentacam post, $\mathrm{mmHg}$ & $17.05(7.9-25.4)$ & I3.15 (II.2-15.7) & 0.016 \\
\hline Air puff post, mmHg & $13.5(10-18)$ & $12.5(10-16)$ & 0.485 \\
\hline ORA post, $\mathrm{mmHg}$ & $16.2(10.2-19.7)$ & $13.45(10.1-15.4)$ & 0.012 \\
\hline Applanation $\Delta, \mathrm{mmHg}$ & $-6.5(-12.0-2.0)$ & $-2.0(-4.0-0.0)$ & $<0.001$ \\
\hline Pentacam $\Delta, \mathrm{mmHg}$ & $-0.95(-2.6-0.4)$ & $-0.65(-1.2-0.2)$ & 0,097 \\
\hline ORA $\Delta, \mathrm{mmHg}$ & $-1.6(-3.5-1.3)$ & $-0.75(-3.5-0.7)$ & 0.007 \\
\hline Air Puff $\Delta, \mathrm{mmHg}$ & $-7.0(-10-3.0)$ & $-2.0(-4.0-1.0)$ & 0.012 \\
\hline
\end{tabular}

Note: Data are presented as median (range), no (\%).

Abbreviations: Pach pre, preoperative pachymetry; ApP pre, preoperative IOP measured by GAT; Pentacam pre, preoperative Pentacam corrected IOP; Air puff pre, preoperative IOP measured by Air puff tonometry; ORA pre, Preoperative ORA IOP; Pach post, postoperative pachymetry; ApP post, postoperative IOP measured by GAT; Pentacam post, postoperative Pentacam corrected IOP; Air puff post, postoperative IOP measured by Air puff tonometry; ORA post, Postoperative ORA IOP ; Applanation $\Delta$, postoperative GAT preoperative value; Pentacam $\Delta$, postoperative Pentacam corrected IOP preoperative value; ORA $\Delta$, postoperative ORA-preoperative value; Airpuff $\Delta$, postoperative Airpuff tonometry value-preoperative value. 
Table 2 Bivariate correlations between app pre and other methods

\begin{tabular}{lllll}
\hline Group & Variable I & Variable 2 & $\mathbf{r}$ & $\boldsymbol{P}$ \\
\hline A & Pach pre, micron & App pre, $\mathrm{mmHg}$ & 0.69 & $0.00 \mathrm{I}$ \\
& Air puff pre, $\mathrm{mmHg}$ & App pre, $\mathrm{mmHg}$ & $0.7 \mathrm{I}$ & $<0.00 \mathrm{I}$ \\
& Pentacam pre, $\mathrm{mmHg}$ & App pre, $\mathrm{mmHg}$ & 0.973 & $<0.00 \mathrm{I}$ \\
& ORA pre, $\mathrm{mmHg}$ & App pre, $\mathrm{mmHg}$ & 0.858 & $<0.00 \mathrm{I}$ \\
$\mathrm{C}$ & Pach pre, micron & App pre, $\mathrm{mmHg}$ & 0.13 & 0.7 \\
& Air puff pre, $\mathrm{mmHg}$ & App pre, $\mathrm{mmHg}$ & 0.88 & $0.00 \mathrm{I}$ \\
& Pentacam pre, $\mathrm{mmHg}$ & App pre, $\mathrm{mmHg}$ & 0.92 & $<0.00 \mathrm{I}$ \\
& ORA pre, $\mathrm{mmHg}$ & App pre, $\mathrm{mmHg}$ & 0.845 & 0.002 \\
Both & Pach pre, micron & App pre, $\mathrm{mmHg}$ & 0.63 & $<0.00 \mathrm{I}$ \\
& Air puff pre, $\mathrm{mmHg}$ & App pre, $\mathrm{mmHg}$ & 0.89 & $<0.00 \mathrm{I}$ \\
& Pentacam pre, $\mathrm{mmHg}$ & App pre, $\mathrm{mmHg}$ & 0.984 & $<0.00 \mathrm{I}$ \\
& ORA pre, mmHg & App pre, $\mathrm{mmHg}$ & 0.92 & $<0.00 \mathrm{I}$ \\
\hline
\end{tabular}

Abbreviation: $r$, Spearman correlation coefficient.

Postoperatively, comparison of the four different IOP measurement methods for LASIK (group B) and EpiLASIK (group D) patients showed a statistically significant difference between their estimated IOP values $(P<0.001$ for group B and 0.045 for group D, Friedman test, Table 3, Figure 2).

Compared with preoperative values, postoperative IOPs measured by the four methods were significantly lower in both LASIK and Epi-LASIK patients (Table 4, Figures 3
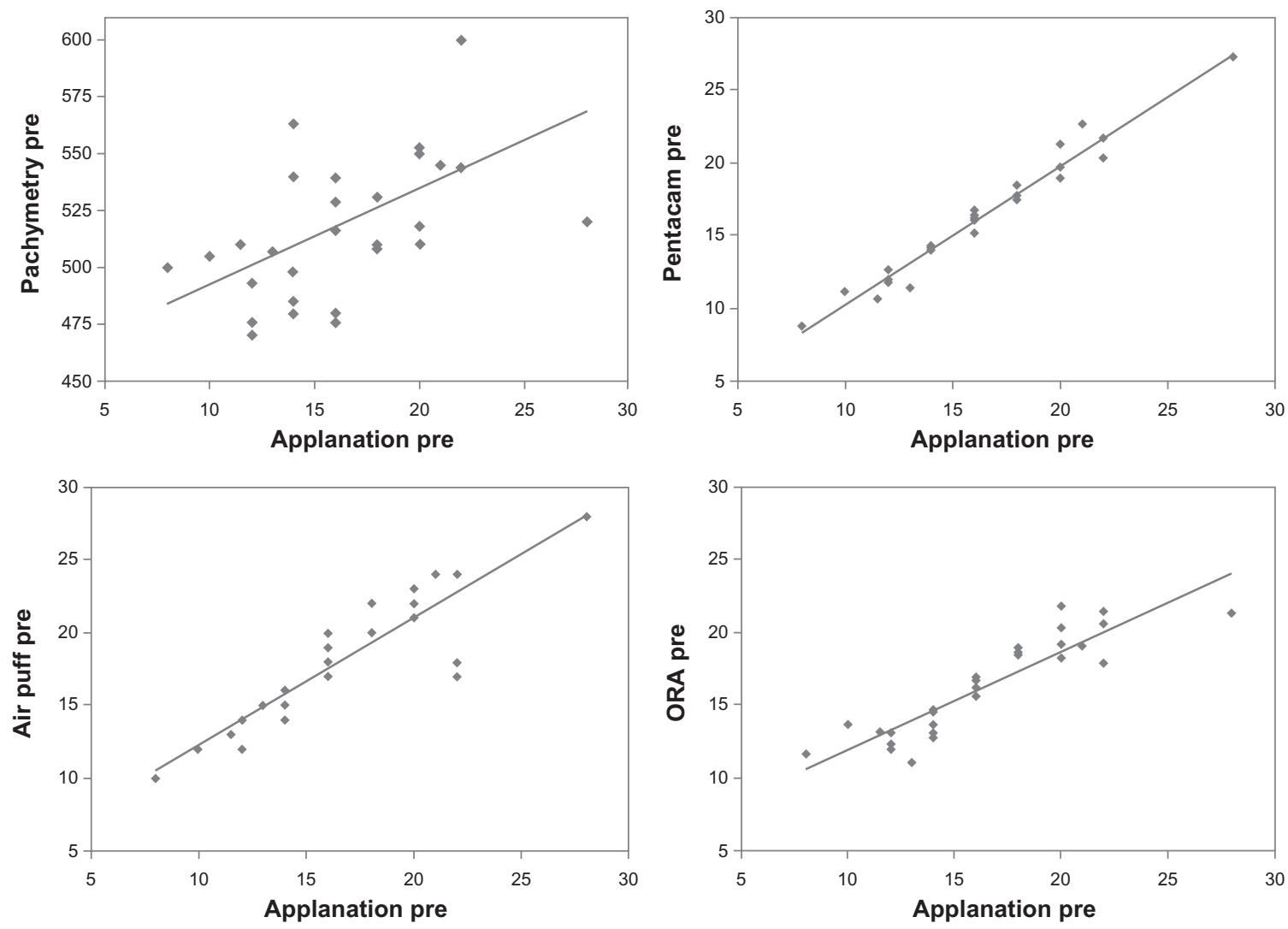

and 4). Interestingly, the difference was particularly evident when IOP was measured using Goldmann applanation and air puff tonometry (median $>6 \mathrm{mmHg}$ for LASIK patients, about $2 \mathrm{mmHg}$ for Epi-LASIK patients), compared with ORA corneal-compensated and Pentacam-corrected IOP (median \pm $1 \mathrm{mmHg}$ for both the LASIK $[P<0.001]$ and Epi-LASIK patients $[P=0.017])$. The degree of IOP-lowering $(\Delta)$ measured using all methods was greater in LASIK patients than in Epi-LASIK patients (Table 4). The Pentacam and ORA methods were nearly equal in accuracy, with a tendency for Pentacam to give more accurate IOP measurements following LASIK and Epi-LASIK, because its $\Delta$ value was lower for all patients.

Our study data showed statistically insignificant correlations between the degree of lowering of postoperative IOP and postoperative pachymetry (central corneal thickness) values in both LASIK (group B) and Epi-LASIK (group D) patients (Table 6). These findings were confirmed by classifying the LASIK group of patients into two subgroups according to median postoperative pachymetry $(461 \mu \mathrm{m})$, and no significant difference was found with regard to the degree of IOP underestimation between these two subgroups (Table 7).

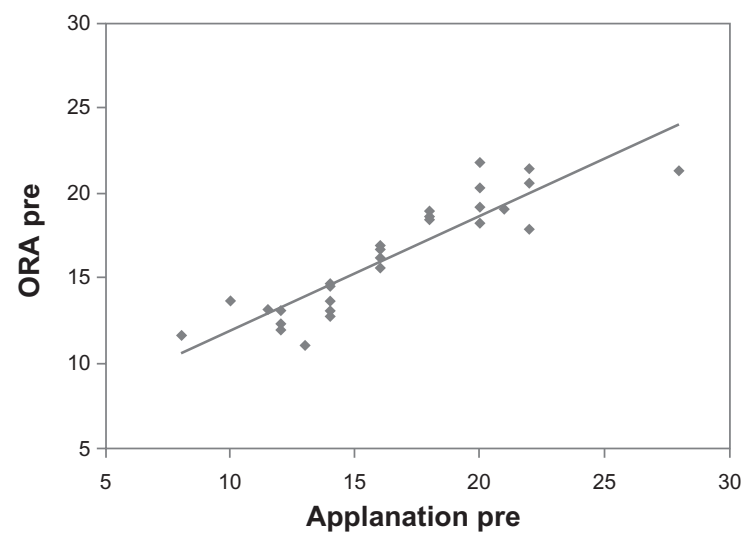

Figure I Bivariate correlations between app pre and other methods in all preoperative study patients collectively (group A and C). 
Table 3 Comparison between postoperative IOP measured by the different methods

\begin{tabular}{llllll}
\hline Group & $\begin{array}{l}\text { Applanation post } \\
\mathbf{m m H g}\end{array}$ & $\begin{array}{l}\text { Pentacam post } \\
\mathbf{m m H g}\end{array}$ & $\begin{array}{l}\text { ORA post } \\
\mathbf{m m H g}\end{array}$ & $\begin{array}{l}\text { Air puff post } \\
\mathbf{m m H g}\end{array}$ \\
\hline B & $12(6-16)$ & $17.05(7.9-25.4)$ & $16.2(10.2-19.7)$ & $13.5(10-18)$ & $<$ \\
$\mathrm{D}$ & $12(10-14)$ & $13.15(11.2-15.7)$ & $13.45(10.1-15.4)$ & $12.5(10-16)$ & 0.045 \\
\hline
\end{tabular}

Note: Data are presented as median (range).

Comparison of pachymetry $\Delta$ (postpreoperative pachymetry value) with IOP $\Delta$ values for each method showed a significant positive linear correlation between each of ORA $\Delta$ and air puff $\Delta$ and pachymetry $\Delta$ in LASIK patients $(r=0.48$ and $r=0.43$, respectively $)$ and a significant moderately strong positive linear correlation between air puff $\Delta$ and pachymetry $\Delta$ in Epi-LASIK patients $(r=0.66$, Table 8$)$.

\section{Discussion}

IOP measurement plays an important role in ophthalmology. Corneal refractive surgery alters corneal thickness and affects corneal biomechanical properties, making measurement of IOP inaccurate. Patients who have had corneal refractive surgery may lose vision due to undiagnosed glaucoma. ${ }^{4}$ In this prospective comparative clinical study, we demonstrated that refractive surgery causes significant lowering of IOP measured using the Goldmann applanation tonometry, air puff tonometry, ORA, and Pentacam methods, with LASIK having more effect on errors of IOP measurement following refractive surgery compared with Epi-LASIK.

Strong positive linear correlations were found in our study between preoperative IOP values measured by Goldmann applanation tonometry and those measured by Pentacam correction (LASIK patients, $\mathrm{r}=0.97, P<0.001$; Epi-LASIK patients, $\mathrm{r}=0.92, P<0.001)$ or by ORA (LASIK patients, $\mathrm{r}=0.858, P<0.001$; Epi-LASIK patients, $\mathrm{r}=0.845, P=0.002)$ prior to refractive surgery. These findings were confirmed by the lack of a significant difference



Figure 2 Comparison between postoperative IOP values in LASIK (group B) and EpiLASIK (group D) patients. between IOP readings estimated by the three methods, and between preoperative Goldmann applanation-Pentacam correction and Goldmann applanation-ORA corneal compensation.

In addition, strong positive linear correlations were found between preoperative pachymetry and Goldmann applanation tonometry values only for LASIK patients $(\mathrm{r}=0.69$, $P=0.001$ ), which may be due to the smaller sample size of the Epi-LASIK group. With regard to air puff tonometry, a significant positive correlation was found with Goldmann applanation tonometry in the current study (LASIK patients, $\mathrm{r}=0.71, P<0.001$; Epi-LASIK patients, $\mathrm{r}=0.88, P=0.001$ ). However, a significant difference was found between preoperative Goldmann applanation and air puff tonometry and between preoperative Goldmann applanation and Pentacam correction.

The results of previous studies are consistent with our finding of a strong correlation between Goldmann applanation tonometry and central corneal thickness, establishing a significant relationship between central corneal thickness and IOP measured with Goldmann applanation tonometry whereby a thick cornea may give a falsely elevated IOP reading and vice versa for a thin cornea. ${ }^{5-9}$ Accordingly, correction tables for Goldmann applanation tonometry according to central corneal thickness are used.

Table 4 Comparison between pre- and postoperative IOP values in LASIK and EpiLASIK patients

\begin{tabular}{|c|c|c|c|c|}
\hline \multirow[t]{2}{*}{ Variable } & \multicolumn{2}{|l|}{ LASIK patients } & \multicolumn{2}{|c|}{ EpiLASIK patients } \\
\hline & IOP, $\mathrm{mmHg}$ & $P$ & IOP, $\mathrm{mmHg}$ & $P$ \\
\hline \multicolumn{5}{|c|}{ Applanation } \\
\hline Pre & I8 (8-28) & $<0.00 \mathrm{I}$ & $14(12-16)$ & 0.007 \\
\hline Post & $12(6-16)$ & & $12(10-14)$ & \\
\hline \multicolumn{5}{|l|}{ ORA } \\
\hline Pre & I8.4 (II.I-2|.9) & $<0.001$ & $13.4(12-16)$ & 0.041 \\
\hline Post & $16.2(10.2-19.7)$ & & $13.45(10.1-15.4)$ & \\
\hline \multicolumn{5}{|l|}{ Pentacam } \\
\hline Pre & $18.15(8.8-27.3)$ & $<0.001$ & $14.05(\mid 1.8-16.2)$ & 0.005 \\
\hline Post & $17.05(7.9-25.4)$ & & $13.15(\mid 1.2-15.7)$ & \\
\hline \multicolumn{5}{|l|}{ Air puff } \\
\hline Pre & $20(10-28)$ & $<0.00 \mathrm{I}$ & $15(12-18)$ & 0.007 \\
\hline Post & $13.5(10-18)$ & & $12.5(10-16)$ & \\
\hline
\end{tabular}

Note: Data are presented as median (range). 


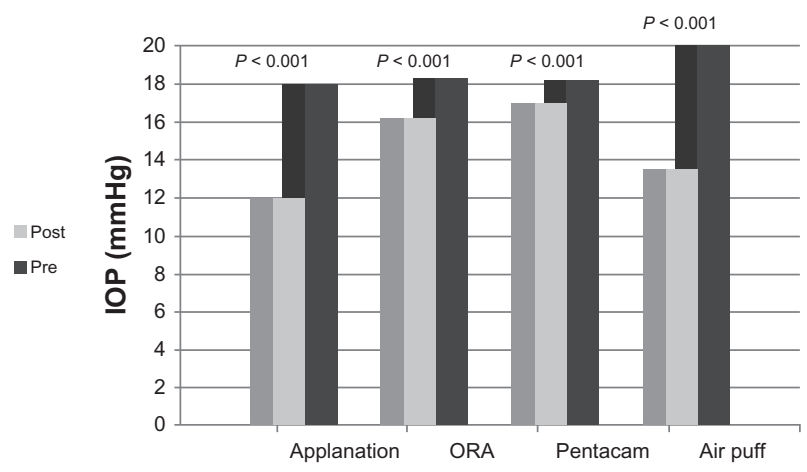

Figure 3 Pre- and postoperative IOP values for the LASIK patients.

In contrast, Myers pointed out that compensation tables often disagree with each other and a lack of correlation between central corneal thickness and IOP can lead clinicians to correct IOP by the wrong magnitude. ${ }^{10}$ Vandewalle et al found no correlation between IOP measurements and central corneal thickness for four instruments, ie, I-care, Pascal dynamic contact tonometry, ORA, and Goldmann applanation tonometry. ${ }^{11}$ However, Liu and Roberts have recently shown that the relationship between central corneal thickness and IOP is nonlinear. Thus, the nomograms cannot fully correct measured IOP based on a single measurement of central corneal thickness, ${ }^{12}$ and there is ongoing debate concerning how much variance in IOP measurement can be explained by central corneal thickness alone..$^{13}$

A strong positive linear correlation was found between preoperative Goldmann applanation tonometry and ORA corneal-compensated IOP measurements in the current study. Similar results were found in earlier research. ${ }^{14}$ Liu et al reported that differences in corneal biomechanics between individuals may contribute more than corneal thickness or curvature to IOP measurement errors. ${ }^{12}$

A significant decrease in postoperative IOP, compared with preoperative values, was found among both LASIK and

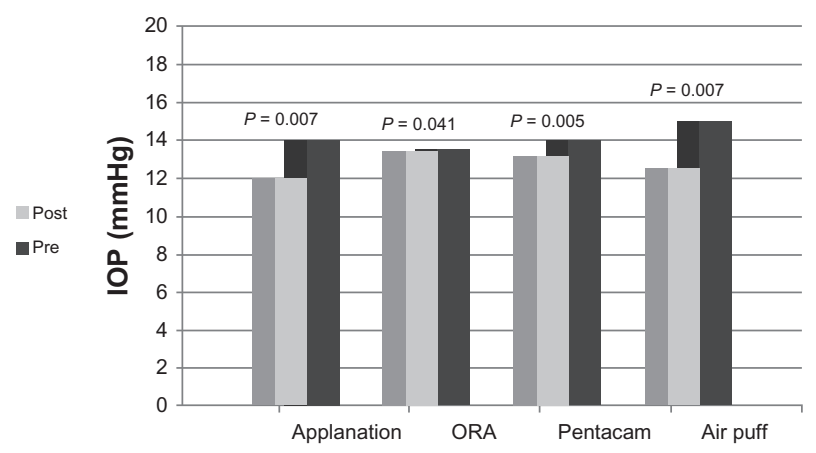

Figure 4 Pre- and postoperative IOP values for the EpiLASIK patients.
Epi-LASIK patients in our study. Similar results have been shown for Goldmann applanation tonometry measurements following LASIK, with some also reporting a significant decrease ${ }^{15-20}$ and others reporting a less pronounced effect $t^{4,9,21}$ after photorefractive keratectomy and laser epithelial keratomileusis (LASEK). ${ }^{19}$ In a study of patients undergoing LASEK only, all tonometry methods showed a small but statistically significant reduction in IOP 3 and 6 months postoperatively. ${ }^{22}$

Interestingly, the decrease in postoperative IOP in the current study (Table 5, Figures 3 and 4) was significant when measured using Goldmann applanation and air puff tonometry compared with IOP measured by ORA and Pentacam. More IOP measurement errors and underestimations using Goldmann applanation tonometry, ORA, Pentacam, and air puff tonometry were seen in the LASIK group than in the Epi-LASIK group. In addition, Goldmann applanation and air puff tonometry underestimated IOP after LASIK by about $6 \mathrm{mmHg}$, while ORA and Pentacam-corrected IOP underestimated IOP by about $1 \mathrm{mmHg}$. Accordingly, the ORA and Pentacam methods were found to be more reliable for measuring IOP following LASIK and Epi-LASIK than were the Goldmann applanation and air puff tonometry methods, a finding supported by the hypothesis that ORA corneal compensated IOP is less influenced by corneal properties such as central corneal thickness and does not appear to drop significantly following LASIK. ${ }^{23}$

Previous studies have found the ORA is helpful for clarifying IOP in patients whose standard tonometry readings are misleading, such as in patients who have had LASIK surgery. In our study, the difference in accuracy between Goldmann applanation tonometry or noncontact tonometry and ORA corneal-compensated IOP readings was apparent in the preoperative and postoperative IOP recordings for LASIK patients. Artificially low Goldmann applanation and noncontact tonometry IOPs are well documented following LASIK because the procedure alters the corneal thickness and composition. However, IOP values before and after LASIK are consistent when they are measured using the ORA method. ${ }^{10,19,20,24-26}$

Regarding the relationship between postoperative pachymetry and the degree of decrease in postoperative IOP, in contrast with most of the previous studies, our study did not show a statistically significant correlation between degree of reduction in postoperative IOP and postoperative pachymetry measurements in LASIK and Epi-LASIK patients. This may be explained by our small patient population and/or inclusion 
Table 5 Difference between post- and preoperative IOP values in LASIK and EpiLASIK patients

\begin{tabular}{|c|c|c|c|c|c|}
\hline & Applanation & Pentacam $\Delta$ & ORA $\Delta$ & Air puff $\Delta$ & $P$ \\
\hline \multirow[t]{2}{*}{ LASIK patients } & -6.5 & -0.95 & -1.6 & -7.0 & $<0.001$ \\
\hline & $(-12.0-2.0)$ & $(-2.6-0.4)$ & $(-3.5-1.3)$ & $(-10-3.0)$ & \\
\hline \multirow[t]{2}{*}{ EpiLASIK patients } & -2.0 & -0.65 & -0.75 & -2.0 & 0.017 \\
\hline & $(-4.0-0.0)$ & $(-1.2-0.2)$ & $(-3.5-0.7)$ & $(-4.0-1.0)$ & \\
\hline
\end{tabular}

Notes: Data are presented as median (range); Applanation $\Delta=$ postoperative GAT - preoperative value; Pentacam $\Delta=$ postoperative Pentacam corrected IOP - preoperative value; ORA.

of a limited myopia range (between -2 and -6 diopters). Inclusion of a wider range of myopia could have resulted in a wider range of ablation, and so a wider range of postoperative pachymetry values.

Comparison of pachymetry $\Delta$ with IOP $\Delta$ values for each method showed a fairly significant positive linear correlation between ORA $\Delta$, air puff $\Delta$, and pachymetry $\Delta$ in LASIK patients and a moderately strong significant positive linear correlation between air puff $\Delta$ and pachymetry $\Delta$ in Epi-LASIK patients, which suggests that the amount of ablation (depending on preoperative error of refraction) can influence the IOP reading following LASIK and Epi-LASIK using these methods.

Muller et al reported that LASIK for myopia produced a mean $3.69 \pm 1.63 \mathrm{mmHg}$ underestimation of IOP when measured by Goldmann applanation tonometry at the central part of the cornea. The decrease in IOP was related to the preoperative IOP and the change in central corneal thickness after LASIK. Thickness of the residual bed appears to influence readings obtained using Goldmann applanation tonometry after myopic LASIK. ${ }^{16}$ Numerous studies have shown that corneal thickness plays an important role among the factors contributing to underestimation of IOP in LASIK patients, ranging from $1.3 \mathrm{~mm} \mathrm{Hg}$ to $6.1 \mathrm{~mm} \mathrm{Hg} .{ }^{27-34}$

Table 6 Bivariate correlations between the degree of lowering of postoperative IOP and postoperative pachymetry value in LASIK (group B) and EpiLASIK (group D) patients

\begin{tabular}{lllll}
\hline Group & Variable I & Variable 2 & $\mathbf{r}$ & $\boldsymbol{P}$ \\
\hline B & Applanation $\Delta$ & Pach post & 0.026 & 0.912 \\
& Pentacam $\Delta$ & Pach post & $-0.25 \mathrm{I}$ & 0.285 \\
& ORA $\Delta$ & Pach post & 0.344 & 0.138 \\
& Air puff $\Delta$ & Pach post & 0.207 & 0.382 \\
D & Applanation $\Delta$ & Pach post & -0.13 & 0.7 \\
& Pentacam $\Delta$ & Pach post & -0.194 & 0.59 \\
& ORA $\Delta$ & Pach post & 0.456 & 0.185 \\
& Air puff $\Delta$ & Pach post & -0.136 & 0.707 \\
\hline
\end{tabular}

Notes: Applanation $\Delta=$ postoperative GAT - preoperative value; Pentacam $\Delta=$ postoperative Pentacam corrected IOP - preoperative value; ORA.
Sánchez-Navés et al reported a highly significant reduction of IOP readings after LASIK for both myopic and hyperopic eyes, and that the reduction was stable one year after LASIK. In the case of myopic eyes, the reduction had a highly significant linear correlation with the amount of tissue ablated in the central region of the cornea because of flap cutting and tissue removal in the central region of the cornea. The mean contribution of flap cutting was estimated to be $1.6 \pm 0.8 \mathrm{mmHg}$, whereas ablation contributes an additional $0.029 \pm 0.003 \mathrm{mmHg}$ per micrometer of removed tissue. ${ }^{35}$

As already mentioned, postoperatively there were underestimations of IOP using all methods, whether after LASIK or Epi-LASIK. The ORA and Pentacam methods were more reliable for measurement of IOP following LASIK. There was more error in IOP measurement and underestimation after LASIK than after Epi-LASIK, but we have to consider the smaller number of Epi-LASIK patients included in our study. The wide variation in age in our patient population was partially overcome by performing the study on the same patients before and after the intervention. Other limitations include our relatively small number of LASIK patients, which may decrease the statistical power and reproducibility of our results, the short period of follow-up after refractive surgery (such patients are easily lost to follow up, especially if they are satisfied with the outcome), and the absence of a reliable reference method for measuring IOP following LASIK, whereas

Table 7 Comparison of the degree of lowering of IOP values in LASIK patients (subgrouped according to median postoperative pachymetry value)

\begin{tabular}{|c|c|c|c|}
\hline \multirow[t]{2}{*}{ Variable } & \multicolumn{2}{|c|}{ LASIK patients $(n=20)$} & \multirow[t]{2}{*}{$P$} \\
\hline & Pach post $>46 \mathrm{I} \mu$ & Pach post $\leq 46 \mathrm{I} \mu$ & \\
\hline Applanation $\Delta$ & $-6.5(-10.0-3.5)$ & $-6.0(-12.0-2.0)$ & 0.739 \\
\hline Pentacam $\Delta$ & $-1.0(-2.3-0.6)$ & $-0.9(-2.6-0.4)$ & 0.9 \\
\hline ORA $\Delta$ & $-1.6(-2.9-1.3)$ & $-1.8(-3.5-0.6)$ & 0.3 \\
\hline Air puff $\Delta$ & $-6.5(-9.0-1.0)$ & $-7.5(-10.0-3.0)$ & 0.73 \\
\hline
\end{tabular}

Note: Data are presented as median (range).

Abbreviation: Pach post, postoperative pachymetry. 
Table 8 Bivariate correlations between the degree of lowering of postoperative IOP and pachymetry $\Delta$ value in LASIK (group B) and EpiLASIK (group D) patients

\begin{tabular}{lllll}
\hline Group & Variable I & Variable 2 & $\mathbf{r}$ & $\boldsymbol{P}$ \\
\hline B & Applanation $\Delta$ & Pach $\Delta$ & 0.32 & 0.17 \\
& Pentacam $\Delta$ & Pach $\Delta$ & -0.5 & 0.8 \\
& ORA $\Delta$ & Pach $\Delta$ & 0.48 & 0.03 \\
& Air puff $\Delta$ & Pach $\Delta$ & 0.43 & 0.057 \\
D & Applanation $\Delta$ & Pach $\Delta$ & 0.55 & 0.1 \\
& Pentacam $\Delta$ & Pach $\Delta$ & 0.5 & 0.14 \\
& ORA $\Delta$ & Pach $\Delta$ & -0.18 & 0.6 \\
& Air puff $\Delta$ & Pach $\Delta$ & 0.66 & 0.036 \\
\hline
\end{tabular}

Notes: Pach $\Delta$, Pachymetry $\Delta=$ post- preoperative pachymetry.

Goldmann applanation tonometry is a reliable reference method to measure IOP prior to any refractive procedure.

To the best of our knowledge, the current study is the first to compare IOP measurements before and after EpiLASIK surgery. Longer-term follow-up of these patients is expected to improve our understanding of the corneal biomechanics involved and their effect on IOP measurements after refractive surgery, and will also help to identify a reliable reference method for measurement of IOP following refractive procedures, especially LASIK.

\section{Disclosure}

The authors report no conflicts of interest in this work.

\section{References}

1. Grødum K, Heijl A, Bengtsson B. A comparison of glaucoma patients identified through mass screening and in routine clinical practice. Acta Ophthalmol Scand. 2002;80:627-631.

2. Kass MA, Heuer DK, Higginbotham EJ, et al. The Ocular Hypertension Treatment Study: a randomized trial determines that topical ocular hypotensive medication delays or prevents the onset of primary openangle glaucoma. Arch Ophthalmol. 2002;120:701-713.

3. Bengtsson B, Leske MC, Hyman L, Heijl A; Early Manifest Glaucoma Trial Group. Fluctuation of intraocular pressure and glaucoma progression in the early manifest glaucoma trial. Ophthalmology. 2007; 114:205-209.

4. Pepose JS, Feigenbaum SK, Qazi MA, et al. Changes in corneal biomechanics and intraocular pressure following LASIK using static, dynamic, and noncontact tonometry. Am J Ophthalmol. 2007;143:39-47.

5. Whitacre MM, Stein R. Sources of errors with use of Goldmann-type tonometers. Surv Ophthalmol. 1993;38:1-30.

6. Medeiros FA, Weinreb RN. Evaluation of the influence of corneal biomechanical properties on intraocular pressure measurements using the ocular response analyzer. J Glaucoma. 2006;15:364-370.

7. Kida T, Liu JH, Weinreb RN. Effect of 24-hour corneal biomechanical changes on intraocular pressure measurement. Invest Ophthalmol Vis Sci. 2006;47:4422-4426.

8. Patwardhan AA, Khan M, Mollan SP, Haigh P. The importance of central corneal thickness measurements and decision making in general ophthalmology clinics: a masked observational study. BMC Ophthalmol. $2008 ; 8: 1$.
9. Uva MG, Reibaldi M, Longo A, et al. Intraocular pressure and central corneal thickness in premature and full-term newborns. $J$ AAPOS. 2011:15:367-369.

10. Myers KJ. Take the next step in tonometry: a new instrument is helping eye care practitioners understand how corneal biomechanics influence the accuracy of IOP measurements. Optometric Management. December 2005.

11. Vandewalle E, Vandenbroeck S, Stalmans I, Zeyen T. Comparison of ICare, dynamic contour tonometer, and ocular response analyzer with Goldmann applanation tonometer in patients with glaucoma. Eur $J$ Ophthalmol. 2009;19:783-789.

12. Liu J, Roberts CJ. Influence of corneal biomechanical properties on intraocular pressure measurement: quantitative analysis. $J$ Cataract Refract Surg. 2005;31:146-155.

13. Kotecha A. What biomechanical properties of the cornea are relevant for the clinician? Surv Ophthalmol. 2007;52 Suppl 2:S109-S114.

14. Carbonaro F, Andrew T, Mackey DA, et al. Comparison of three methods of intraocular pressure measurement and their relation to central corneal thickness. Eye (Lond). 2010;24:1165-1170.

15. Kaufmann C, Bachmann LM, Thiel MA. Intraocular pressure measurements using dynamic contour tonometry after laser in situ keratomileusis. Invest Ophthalmol Vis Sci. 2003;44:3790-3794.

16. Muller L, Kohnen T. Influence of residual corneal bed thickness after myopic LASIK on intraocular pressure measurements. Goldmann applanation tonometry and dynamic contour tonometry. Ophthalmologe. 2009;106:21-28. German.

17. Ho T, Cheng AC, Rao SK, et al. Central corneal thickness measurements using Orbscan II, Visante, ultrasound, and Pentacam pachymetry after laser in situ keratomileusis for myopia. J Cataract Refract Surg. 2007;33:1177-1182.

18. Siganos DS, Papastergiou GI, Moedas C. Assessment of the Pascal dynamic contour tonometer in monitoring intraocular pressure in unoperated eyes and eyes after LASIK. J Cataract Refract Surg. 2004;30: 746-751.

19. Svedberg H, Chen EH, Hamberg-Nyström H. Changes in corneal thickness and curvature after different excimer laser photorefractive procedures and their impact on intraocular pressure measurements. Graefes Arch Clin Exp Ophthalmol. 2005;243: $1218-1220$.

20. Kirwan C, O'Keefe M. Measurement of intraocular pressure in LASIK and LASEK patients using the Reichert ocular response analyzer and Goldmann applanation tonometry. $J$ Refract Surg. 2008;24: 366-370.

21. Shemesh G, Man O, Michaeli A, et al. Pressure phosphene tonometry versus Goldmann applanation tonometry for measuring intraocular pressure before and after LASIK. J Refract Surg. 2007;23: 405-409.

22. Jóhannesson G, Hallberg P, Eklund A, et al. Change in intraocular pressure measurement after myopic LASEK: a study evaluating Goldmann, Pascal and applanation resonance tonometry. J Glaucoma. 2012;21(4):255-259.

23. Goldberg L. The Ocular Response Analyzer. 2005. Available from: http://www.ophthalmologymanagement.com/articleviewer. aspx?articleID=86422. Accessed March 25, 2012.

24. Duch S, Serra A, Castanera J, et al. Tonometry after laser in situ keratomileusis treatment. J Glaucoma. 2001;10:261-265.

25. Duba I, Wirthlin AC. Dynamic contour tonometry for post-LASIK intraocular pressure measurements. Klin Monbl Augenheilkd. 2004;221:347-350. German.

26. Yang CC, Wang IJ, Chang YC, et al. A predictive model for postoperative intraocular pressure among patients undergoing laser in situ keratomileusis (LASIK). Am J Ophthalmol. 2006;141: 530-536.

27. Chihara E, Takahashi H, Okazaki K, et al. The preoperative intraocular pressure level predicts the amount of underestimated intraocular pressure after LASIK for myopia. Br J Ophthalmol. 2005;89:160-164. 
28. Park HJ, Uhm KB, Hong C. Reduction in intraocular pressure after laser in situ keratomileusis. J Cataract Refract Surg. 2001;27:303-309.

29. Fournier AV, Podtetenev M, Lemire J, et al. Intraocular pressure change measured by Goldmann tonometry after laser in situ keratomileusis. $J$ Cataract Refract Surg. 1998;24:905-910.

30. Montés-Micó R, Charman WN. Intraocular pressure after excimer laser myopic refractive surgery. Ophthalmol Physiol Opt. 2001;21: 228-235.

31. El Danasoury MA, El Maghraby A, Coorpender SJ. Change in intraocular pressure in myopic eyes measured with contact and noncontact tonometers after laser in situ keratomileusis. J Refract Surg. 2001;17:97-104

32. Gimeno JA, Muñoz LA, Valenzuela LA, et al. Influence of refraction on tonometric readings after photorefractive keratectomy and laser assisted in situ keratomileusis. Cornea. 2000;19:512-516.
33. Emara B, Probst LE, Tingey DP, et al. Correlation of intraocular pressure and central corneal thickness in normal myopic eyes and after laser in situ keratomileusis. J Cataract Refract Surg. 1998;24: $1320-1325$.

34. Arimoto A, Shimizu K, Shoji N, Enomoto K, Kohara M. Underestimation of intraocular pressure in eyes after laser in situ keratomileusis. Jpn J Ophthalmol. 2002:46:645-649.

35. Sánchez-Navés J, Furfaro L, Piro O, Balle S. Impact and permanence of LASIK-induced structural changes in the cornea on pneumotonometric measurements: contributions of flap cutting and stromal ablation. J Glaucoma. 2008;17:611-618.
Clinical Ophthalmology

\section{Publish your work in this journal}

Clinical Ophthalmology is an international, peer-reviewed journal covering all subspecialties within ophthalmology. Key topics include: Optometry; Visual science; Pharmacology and drug therapy in eye diseases; Basic Sciences; Primary and Secondary eye care; Patien Safety and Quality of Care Improvements. This journal is indexed on

Submit your manuscript here: http://www.dovepress.com/clinical-ophthalmology-journal

\section{Dovepress}

PubMed Central and CAS, and is the official journal of The Society of Clinical Ophthalmology (SCO). The manuscript management system is completely online and includes a very quick and fair peer-review system, which is all easy to use. Visit http://www.dovepress.com/ testimonials.php to read real quotes from published authors. 